\title{
Pro-actieve zorg voor kwetsbare ouderen: terug bij af?
}

In het kader van het Nationaal Programma Ouderenzorg zijn verspreid over Nederland negen programma's ontwikkeld om de proactieve zorg voor kwetsbare ouderen te verbeteren. Deze beogen om vroegtijdig problemen en risico's aan te pakken om daarmee een achteruitgang in functioneren te vertragen en opname in een zorginstelling te vermijden. Het opsporen van kwetsbare ouderen, gevolgd door een interdisciplinaire aanpak op maat, vindt daarbij plaats in - of is nauw gelieerd aan - de huisartsenpraktijk. In de afgelopen jaren is de aanpak in iedere regio geëvalueerd in gecontroleerde onderzoeken waaraan tevens procesevaluaties gekoppeld waren.

Ondanks accentverschillen in de programma's zijn de bevindingen over de regio's consistent. Ze blijken weinig of geen overtuigende effecten te hebben op de gezondheid en het functioneren van de ouderen (noch hun mantelzorgers) en een substitutie-effect in zorggebruik en kosten blijft eveneens uit. De betrokken ouderen en hulpverleners zijn in de regel wel tevreden over de ontvangen en verleende zorg en ondersteuning. Deze bevindingen geven aan dat het op de huidige manier continueren van de programma's niet zinvol is. Nadere analyses wijzen erop dat een eenvoudigere aanpak, gericht op specifiekere risicogroepen, de voorkeur lijkt te verdienen.

\section{PRO-ACTIEVE OUDERENZORG}

Om bekende redenen is de aandacht voor ouderenzorg in de afgelopen jaren sterk toegenomen. Met de vergrijzing neemt ook het aantal ouderen met complexere en meervoudige problematiek toe, terwijl beschikbare beroepskrachten en budgetten sterk onder druk (komen te) staan. Ter verlichting van dit spanningsveld wordt onder meer veel verwacht van proactieve ouderenzorg, met een sleutelrol voor huisartsen en aan hen gelieerde hulpverleners. Zijn we in staat om vroegtijdig problemen en risico's bij ouderen te signaleren en aan te pakken, zodat een (verdere) achteruitgang in functioneren vertraagd of uitgesteld kan worden en zij langer en tegen geringere zorgkosten thuis kunnen blijven wonen?

Aandacht voor proactieve ouderenzorg in de eerste lijn is niet nieuw. Ruim veertig jaar geleden beschreven huisartsen al hun aanpak om ouderen die hun praktijk niet of nauwelijks bezochten systematisch in kaart te brengen en thuis te bezoeken. Friendly visiting sluit als benadering aan op die gedachte. Ook vanuit andere disciplines werd, al dan niet systematisch, ingezet op het proactief in contact komen met ouderen zonder of voordat daar een expliciete hulpvraag aan vooraf ging. Zo werden er tot circa 1995 vanuit de wijkverpleging op grote schaal preventieve ouderenbezoeken uitgevoerd (bijvoorbeeld jaarlijks bij alle thuiswonende 70 - of 75 -plussers). Vergelijkbare vormen van vroegsignalering werden uitgevoerd vanuit gemeenten en vrijwilligersorganisaties en als experiment verschenen er op enkele plaatsen in Nederland zelfs consultatiebureaus voor ouderen.
Deze initiatieven zijn in de loop der tijd vrijwel allemaal gestaakt. Met de start in 2008 van het Nationaal Programma Ouderenzorg (NPO), met een initieel budget van 80 miljoen euro, heeft het ministerie van VWS een flinke impuls gegeven aan het verbeteren van de complexe ouderenzorg (c.q. de zorg voor kwetsbare ouderen). In ieder van de acht academische regio's zijn eerst netwerken ingericht om alle relevante partijen te verbinden. Vanuit die netwerken zijn vervolgens innovatieve zorgmodellen en interventies ontwikkeld en geëvalueerd (in totaal zo'n 75 transitie-, onderzoeks- en implementatieprojecten). In de eerste tranche projecten stonden vooral proactieve integrale zorgmodellen vanuit de huisartsenpraktijk centraal.

We zijn nu bijna tien jaar verder en de resultaten van deze eerste tranche projecten zijn bekend. Een goed moment om te bezien wat de inspanningen rond proactieve integrale ouderenzorg hebben opgeleverd en welke implicaties dat heeft voor de huisartsenzorg. We beperken ons daarbij tot programma's die op de algemene populatie van thuiswonende ouderen zijn gericht, en niet op specifieke doelgroepen zoals ouderen met dementie.

\section{KENMERKEN PROJECTEN OUDERENZORG}

In de acht regio's zijn in totaal negen zorgprogramma's ontwikkeld. ${ }^{2-11}$ Daarin worden kwetsbare ouderen opgespoord, waarna een behandelplan op maat voor gesignaleerde problemen en risico's opgesteld en uitgevoerd wordt. De afstemming en coördinatie van de veelal interdisciplinaire aanpak vindt plaats in (of anders in nauw overleg met) de huisartsenpraktijk. Praktijkondersteuners $(\mathrm{POH})$, praktijkverpleegkundigen en/of wijkverpleegkundigen zijn vaak de spil in de uitvoering van het zorgprogramma. Hoewel de precieze invulling van de negen programma's wat verschilt, komen vijf kernelementen overeen: ${ }^{12}$

- Selectie/identificatie van kwetsbare ouderen

- Assessment van gesignaleerde problemen en risico's

- Formuleren van doelen en plan van aanpak (door een interdisciplinair team)

- Uitvoering plan

- Monitoring van voortgang (en waar nodig aanpassen doelen en/of aanpak)

In sommige modellen was tevens aandacht voor een betere transfer naar en uit het ziekenhuis.

Verschillen in de invulling betreffen vooral de screenings-

Zuyd Hogeschool, Nieuw Eyckholt 30o, 6419 DJ Heerlen: dr. E. van Rossum, lector Zorginnovaties voor kwetsbare ouderen; programmaleider Wijkgerichte Zorg en Samenwerking van het Expertisecentrum voor Innovatieve Zorg en Technologie; senior onderzoeker bij Universiteit Maastricht, vakgroep Health Services Research en Academische Werkplaats Ouderenzorg Zuid-Limburg. VU medisch centrum, EMCO+ Instituut, afdeling Huisarts- en Ouderengeneeskunde: dr. H.P. van Hout, universitair hoofddocent • Correspondentie: erik.vanrossum@zuyd.nl • Belangenverstrengeling: niets aangegeven. 


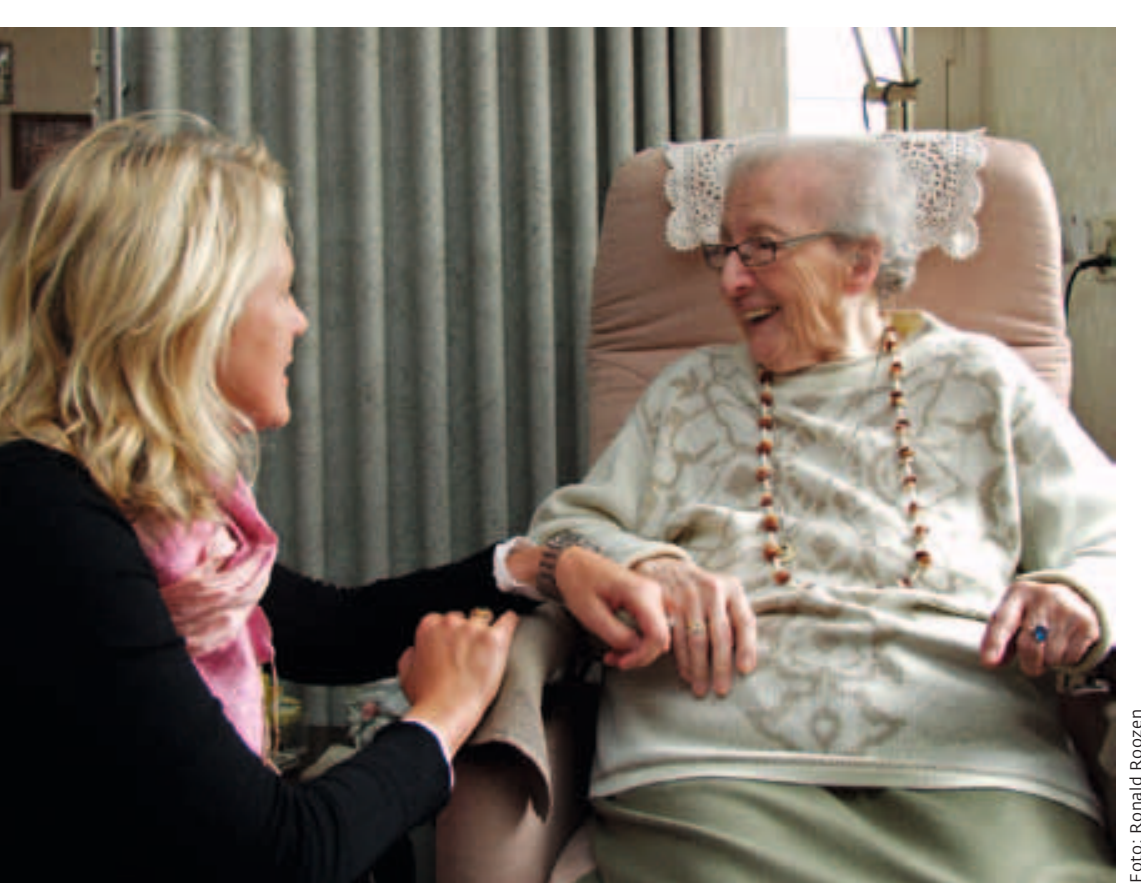

tools die gebruikt worden, de intensiteit van cliëntcontacten (met name huisbezoeken) en de mate waarin andere disciplines (naast de huisarts en $\mathrm{POH}$ of praktijkverpleegkundige) deel uitmaken van het behandelteam. ${ }^{13} \mathrm{Zo}$ is in vrijwel ieder programma een andere screeningsprocedure gehanteerd, variërend van geautomatiseerde risicodetectie op basis van in de huisartsenpraktijk beschikbare registratiegegevens (Om U in Utrecht), periodieke afname van een gestandaardiseerde vragenlijst door de $\mathrm{POH}$ (Geriatrisch Zorgmodel in Amsterdam), tot zelfrapportage van ouderen op basis van een korte screeningslijst zoals de GFI of Easycare TOS (onder andere Zorg uit Voorzorg in de Westelijke Mijnstreek en Zorg en WelzijnsStandaard in Nijmegen).

Rond 2009 zijn de eerste effectonderzoeken naar deze nieuwe zorgmodellen gestart. Ook deze komen qua opzet en uitvoering heel goed overeen, mede door enkele expliciete subsidievoorwaarden van ZonMw als uitvoerder van het NPO (denk aan standaard batterij aan meetinstrumenten voor metingen bij zowel ouderen als mantelzorgers). In veruit de meeste gevallen gaat het om clustergerandomiseerde onderzoeken waarin toewijzing aan groepen plaatsvond op het niveau van de huisartsenpraktijk. Steeds zijn effecten van de programma's gemeten bij ouderen en mantelzorgers. Daarbij werd een uitgebreid palet aan gezondheidsindicatoren in kaart gebracht (inclusief kwaliteit van leven), evenals het zorggebruik. Op basis daarvan is in ieder project de kosteneffectiviteit bepaald. De omvang van de onderzoeken qua aantallen ouderen en huisartsenpraktijken verschilt per regio, maar meestal gaat het om substantiële aantallen ouderen (variërend van zo'n 150 tot circa 1500 ouderen per groep, met een gemiddelde leeftijd van rond de 80 jaar). In iedere regio is aan de effectevaluatie een procesevaluatie gekoppeld om de implementatie en ervaringen van ouderen, mantelzorgers en betrokken hulpverleners te monitoren.

\section{OPBRENGSTEN NPO-PROJECTEN}

Uit alle uitgevoerde onderzoeken komen weinig overtuigende en consistente effecten van de programma's op het functioneren van ouderen en hun mantelzorgers naar voren. Dat geldt ook voor hun impact op het zorggebruik (mogelijk substitutieeffect). Soms is weliswaar een statistisch significant effect op een uitkomstmaat gevonden, bijvoorbeeld op dagelijks functioneren (Om U en Geriatrisch Zorgmodel) of een subschaal van kwaliteit van leven (vriendschap \& liefde, Walcheren Integrale Zorgmodel), maar de klinische betekenis van de gevonden verschillen lijkt in die gevallen beperkt. Dat geldt ook voor de kosteneffectiviteit. Een recente review van enige NPOonderzoeken geeft aan dat de Utrechtse en Nijmeegse onderzoeksgroepen weliswaar rapporteren dat hun programma's mogelijk kosteneffectief zijn, maar dat ze tegelijkertijd geen harde conclusies trekken over het geconstateerde verschil in zorgkosten. ${ }^{13}$

Consistenter - en positiever - zijn de bevindingen uit de procesevaluaties. Daaruit komt een veel rooskleuriger beeld naar voren. Ouderen en mantelzorgers zijn over het algemeen (erg) tevreden over de ontvangen zorg en ondersteuning. Dat geldt in iets mindere mate ook voor de betrokken hulpverleners; men vindt het programma vaak een flinke inspanning, maar het leidt wel tot een beter zicht op de ouderenpopulatie, specifieke cliëntsituaties en sterkere verbindingen tussen de betrokken disciplines.

Al met al valt de opbrengst van de programma's in termen van (kosten)effectiviteit tegen. $\mathrm{Nu}$ is de evaluatie van dergelijke complexe innovaties niet eenvoudig. Dat blijkt ook uit de uitgevoerde NPO-onderzoeken wanneer bijvoorbeeld naar uitval en compliance met programmaonderdelen wordt gekeken. Ook is discussie over de selectie van de juiste doelpopulatie en de vraag of onze standaard meetinstrumenten wel goed in staat zijn om relevante veranderingen boven tafel te krijgen. Van de andere kant: de onderzoeken zijn volgens gangbare en breed erkende methodologie opgezet en uitgevoerd en ondanks verschillen in gebruikte identificatietools en interventie-strategieën zijn de resultaten consistent over alle onderzoeken. Bovendien zijn de onderzoeken door ervaren onderzoeksgroepen uitgevoerd en is in alle regio's veel energie gestoken in de optimale vormgeving van het programma. Daarbij werd zoveel mogelijk aangehaakt bij lokale mogelijkheden en al beschikbare initiatieven. Indien in deze omgevingen geen overtuigende effecten gevonden worden is de kans erg klein dat die elders wel overtuigend te behalen zijn.

Voor de meeste zorgverzekeraars is dit alles overigens geen reden om de financiering van activiteiten in het kader van de proactieve ouderenzorg te staken. Voordat effecten bekend werden boden deze verzekeraars huisartsen al de mogelijkheid om in te schrijven op modules (complexe) ouderenzorg. Daar is en wordt nog steeds - voor zover ons bekend - op vrij grote schaal gebruik van gemaakt. Zo maakt 51\% van de huisartsen die met verzekeraar CZ een overeenkomst hebben voor het leveren van huisartsenzorg gebruik van een van de beschikbare ouderenmodulevarianten. Een adviesbureau heeft 
in opdracht van ZonMw inmiddels uitgezocht hoe structurele financiering van de in het NPO ontwikkelde initiatieven te realiseren zou zijn. ${ }^{14}$

\section{HOE NU VERDER?}

Tien jaar ontwikkeling en evaluatie van deze proactieve ouderenzorgprogramma's in het NPO laat zien dat ze vanuit klinisch en kostenoogpunt weinig of geen impact hebben. De betrokken ouderen en hulpverleners zijn er over het algemeen wel tevreden over en de zorgverzekeraars faciliteren ze financieel. Dat betekent niet dat het NPO weinig heeft opgeleverd. Het heeft zeker bijgedragen aan de regionale netwerkvorming en er is op veel fronten hard gewerkt aan de vormgeving en evaluatie van nieuwe zorgmodellen, ook buiten dan wel in verbinding met het extramurale zorgveld. Daarbij is veel aandacht besteed aan specifieke onderdelen van deze modellen (onder andere screening, assessment en interprofessionele samenwerking).

Desondanks kampen we ook na tien jaar nog steeds met enkele fundamentele vragen, onder meer over de identificatie van risico's en risicogroepen, de goede match van interventies bij specifieke risico's of stadia van kwetsbaarheid, en de complexiteit van onze interventiestrategieën (overvragen we niet de betrokken hulpverleners?).

Hoe nu verder? Het is niet zinvol om de in de NPO-programma's ontwikkelde aanpak te continueren. Op basis van de opgedane ervaringen kunnen ze wel op bescheidener schaal, en toegespitst op specifiekere doelgroepen, doorontwikkeld worden. Zo kan de screening op populatieniveau, gericht op bijvoorbeeld alle 70-plussers in de huisartsenpraktijk, met de huidige tools gestaakt worden. Die screening is relatief tijdrovend, duur en inefficiënt doordat nog te vaak een andere (minder of tijdelijk kwetsbare) doelgroep geselecteerd wordt dan beoogd. Bij de identificatie van ouderen zou veel meer aangehaakt kunnen worden bij het frequente contact dat de meeste ouderen toch al met de huisarts(enpraktijk) hebben; in 2014 was dit voor alle 75-plussers gemiddeld om de vijf à zes weken. ${ }^{15}$

Uit eerste meta-analyses van gegevens uit NPO-projecten komen indicaties dat de programma's wat meer impact lijken te hebben op hoogrisicogroepen zoals de oudste leeftijdsgroepen $(80+)$, alleenstaanden en personen die thuiszorg ontvangen. ${ }^{13}$ De Groningse Samen Oud-studie heeft dit recentelijk bevestigd. Voorlopig zou vooral op deze subgroepen ingezet kunnen worden. Daaraan gekoppeld zou vanuit een oogpunt van kostenreductie meer ingestoken kunnen worden op personen met een verhoogd risico op het gebruik van dure zorg (ziekenhuis- en verpleeghuisopnamen). Op basis van NPOgegevens uit een groot aantal onderzoeken is het inmiddels steeds beter mogelijk om risicoprofielen op te stellen. Ook deze zouden gebruikt kunnen worden voor de gerichte selectie van ouderen. De uitdaging blijft dan nog steeds bestaan om geschikte ondersteuningstrajecten op maat aan te bieden. Dit werkt bijvoorbeeld goed bij personen met dementie, waar casemanagement zeer kosteneffectief blijkt te zijn. Het leidt tot grote besparingen, onder meer door uitstel van verpleeghuisopnames en lagere tijdsbelasting van naasten. ${ }^{16}$ Daarbij speelt de manier waarop casemanagement is georganiseerd ook een belangrijke rol. Regio's waar casemanagers zijn ingebed in multidisciplinaire teams zijn in staat om naast besparingen ook de kwaliteit van leven te bevorderen.

Resumerend pleiten we voor het in kleine stapjes verder ontwikkelen van proactieve zorg voor kwetsbare ouderen. Grote zorgtransities zijn vooral vanaf 2015 ingezet, ruim nadat de eerste NPO programma's zijn ontwikkeld en geïmplementeerd. We zijn inmiddels in een nieuwe context beland, waarin meer kwetsbare mensen langer thuis (moeten) blijven. De eerste hulpen in het land stromen momenteel over met oudere personen. Dat is een noodsignaal dat aangeeft dat het belangrijk is om te blijven werken aan betere eerstelijns ondersteuning voor ouderen.

\section{LITERATUUR}

1 Rijksinstituut voor Volksgezondheid en Milieu. Vroegopsporing bij (kwetsbare) ouderen; op weg naar betere aansluiting bij wat ouderen zelf willen en kunnen. Bilthoven: RIVM, 2014.

2 Hoogendijk EO, Van der Horst HE, Van de Ven PM, Twisk JW, Deeg DJ, Frijters DH, et al. Effectiveness of a Geriatric Care Model for frail older adults in primary care: Results from a stepped wedge cluster randomized trial. Eur J Intern Med 2016;28:43-51.

3 Stijnen MNM. Towards proactive care for potentially frail older people in general practice. Maastricht: Datawyse / Universitaire Pers Maastricht, 2015.

4 Blom J, Den Elzen W, Van Houwelingen AH, Heijmans M, Stijnen T, Van den Hout W, et al. Effectiveness and cost-effectiveness of a proactive, goaloriented, integrated care model in general practice for older people. A cluster randomised controlled trial: Integrated Systematic Care for older People - the ISCOPE study. Age Ageing 2016;45(1):30-41.

5 Looman WM, Fabbricotti IN, Huijsman R. The short-term effects of an in tegrated care model for the frail elderly on health, quality of life, health care use and satisfaction with care. Int J Integr Care 2014;14:1-11.

6 Bleijenberg N. Personalized primary care for older people: an evaluation of a multicomponent nurse-led care program. Utrecht: University Medical Center Utrecht, 2013.

7 Drubbel I. Frailty screening in older patients in primary care using routine care data. Utrecht: University Medical Center Utrecht, 2013.

8 Ruikes FGH, Zuidema SU, Akkermans RP, Assendelft WJJ, Schers HJ, Koop mans RTCM. Multicomponent program to reduce functional decline in frail elderly people: a cluster controlled trial. J Am Board Fam Med 2016;29(2):209-17.

9 Metzelthin SF, Van Rossum E, De Witte LP, Ambergen AW, Hobma SO, Si pers $\mathrm{W}$, et al. Effectiveness of interdisciplinary primary care approach to reduce disability in community dwelling frail older people: cluster randomised controlled trial. Br Med J 2013;347:f5264.

10 Spoorenberg SLW, Uittenbroek RJ, Middel B, Kremer BPH, Reijneveld SA, Wynia K. Embrace, a model for integrated elderly care: study protocol of a randomized controlled trial on the effectiveness regarding patient outcomes, service use, costs, and quality of care. BMC Geriatrics 2013;13(62):1-11.

11 Suiker J, Buurman BM, Ter Riet G, Van Rijn M, De Haan RJ, De Rooij SE, et al. Comprehensive geriatric assessment, multifactorial interventions and nurse-led care coordination to prevent functional decline in communitydwelling older persons: protocol of a cluster randomized trial. BMC Health Serv Res 2012;12 (85):1-12.

12 Metzelthin S, Daniëls R. Interventies en effectiviteit (theorie). In: Van der Ploeg ES, Gobbens RJJ, redactie. Werken met thuiswonende kwetsbare ouderen. Houten: Bohn Stafleu van Loghum, 2016.

13 Van Hout H. Eerstelijns- en wijkgerichte ouderenzorg: onderbouwing voor een integrale vernieuwingsstrategie in Amsterdam. Amsterdam: Ben Sajet Centrum, 2016.

14 Zorgmarkt Advies. Stappenplan realiseren structurele financiering innovatieve ouderenzorg. Amsterdam, juni 2016.

15 http://www.nivel.nl/nl/nzr/contacten-huisartsenpraktijk [cijfers over 2014].

16 MacNeil-Vroomen JL, Bosmans JE, Eekhout JE, Eekhout I, Joling KJ, Van Mierlo LD, et al. The cost-effectiveness of two forms of case management compared to a control group for persons with dementia and their informal caregivers from a social perspective. PlosOne 2016 (accepted). 